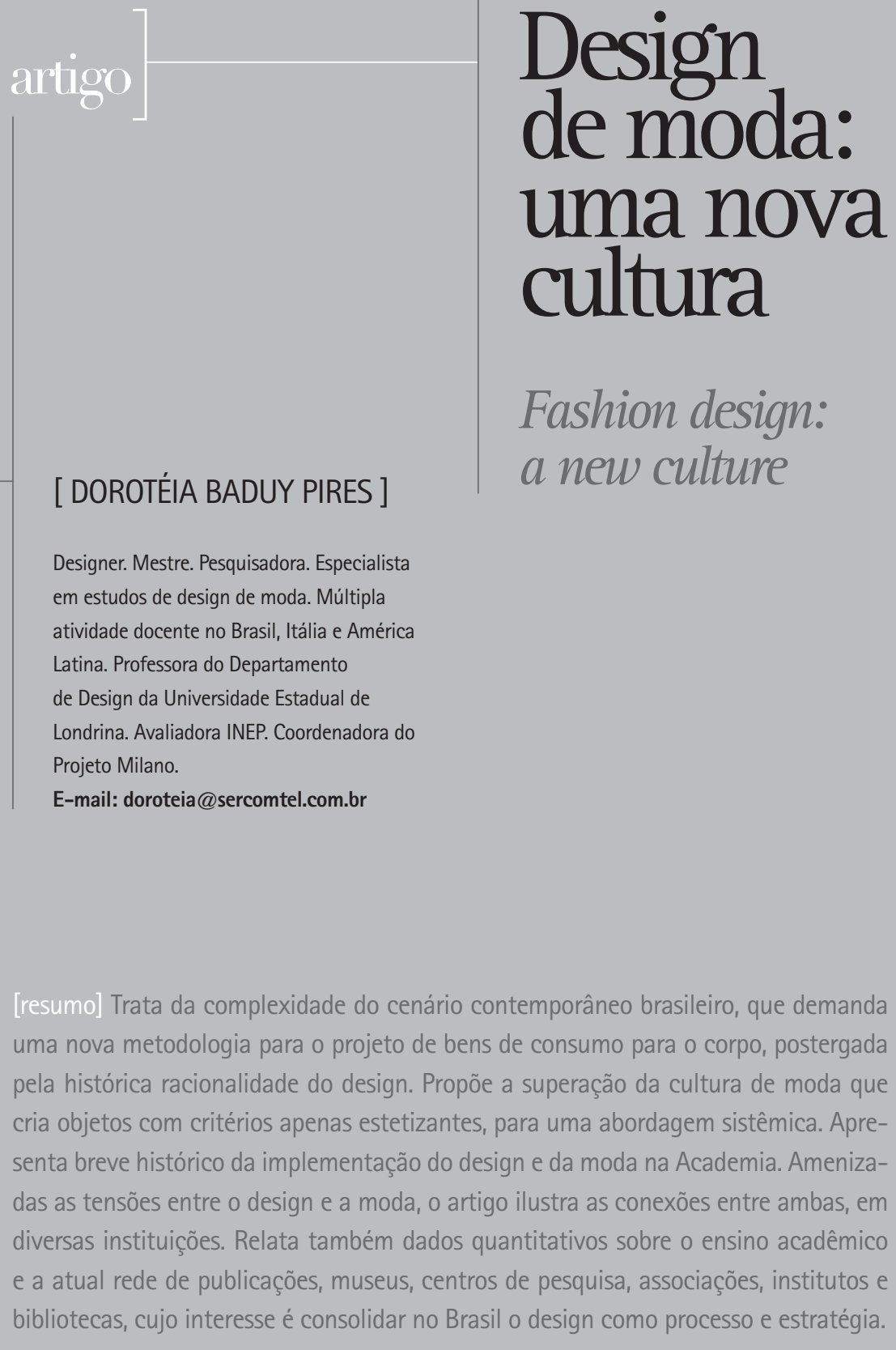

\title{
Design de moda: uma nova cultura
}

\author{
Fashion design: \\ a new culture
}

Designer. Mestre. Pesquisadora. Especialista em estudos de design de moda. Múltipla atividade docente no Brasil, Itália e América Latina. Professora do Departamento de Design da Universidade Estadual de Londrina. Avaliadora INEP. Coordenadora do Projeto Milano.

E-mail: doroteia@sercomtel.com.br

[resumo] Trata da complexidade do cenário contemporâneo brasileiro, que demanda uma nova metodologia para o projeto de bens de consumo para o corpo, postergada pela histórica racionalidade do design. Propõe a superação da cultura de moda que cria objetos com critérios apenas estetizantes, para uma abordagem sistêmica. Apresenta breve histórico da implementação do design e da moda na Academia. Amenizadas as tensões entre o design e a moda, 0 artigo ilustra as conexões entre ambas, em diversas instituições. Relata também dados quantitativos sobre o ensino acadêmico e a atual rede de publicações, museus, centros de pesquisa, associações, institutos e bibliotecas, cujo interesse é consolidar no Brasil o design como processo e estratégia.

[palavras-chave ]

design; moda; cultura; projeto; educação.

[abstract] It is about the complexity of the Brazilian contemporaneous scenery, that demands a new methodology for the consumption goods project to the body, postponed by the historical rationality of design. It proposes the overcoming of the fashion culture that creates objects with no more than esthetic criterions, to a systematic approach to the subject. It presents a brief historical of the implementation of the of the design and of the fashion in the Academy. With the tensions between design and fashion calmed down, the article illustrates the connections between both of them, in many different situations. It also shows quantitative data about the academic teaching and the latest net of publications, museums, research centers, associations, institutes and libraries, whose interest is to consolidate in Brazil, design as a process and strategy.

[key words] design; fashion; cultures, project; education. 
A demanda do mercado foi fator determinante no estabelecimento dos cursos universitários de design de moda no Brasil. Porém, outras questões como a crescente cultura do corpo, da aparência, a segmentação do mercado e do consumidor passaram a exigir uma nova metodologia e, com isto, um profissional com um perfil muito diferente do que a indústria adotava até então.

Durante alguns anos, o estilismo correspondeu a tal demanda; porém, a realidade atual requer uma abordagem sistêmica, o que consagra a importância do design.

Para De Angelis (Strada, 1998), a lógica da moda e do design se apresentam como sintese e ao mesmo tempo metáfora dos cenários dominados pela estética. Sobre a estreita relação entre a moda e o design, De Angelis afirma que constituem dois mundos complementares e simbióticos, dois mundos distantes, mas contemporaneamente afins. Moda e design estão ligados pelo mundo do projeto, pelo impulso do desejo, pelo mecanismo de sedução e estilo de vida dos usuários. Diferem nos seus tempos de consumo e de fruição e pela complexidade dos sistemas. No entanto, em alguns domínios ambos se assemelham, a exemplo dos acessórios, dos artigos esportivos, das lingeries e dos calçados. São objetos que resultam de um projeto que busca criar beleza e emoção.

0 vestuário ainda é tema pouco presente na história do design. Segundo Christopher Breward (Vaccari, 2003), ainda hoje há efeitos da formulação racionalizante da fase inicial do design. Apesar de também ter sido discriminado pela maioria dos grupos, existem alguns pontos de contato entre o vestuário e o design; isto é, moda e design sempre compartilharam as mesmas idéias de urbanidade e civilização, assim como o mesmo entusiasmo pela inovação e pelo progresso. Para Vaccari (2003), a perspectiva do design pode contribuir em termos metodológicos ao estilismo de moda.

Como o impulso da industrialização no Brasil se deu tardiamente, entre as duas grandes Guerras Mundiais, é factível que o primeiro curso de Desenho Industrial também tenha surgido tarde, em 1963. Assim, o primeiro curso da América Latina foi criado com o nome de Esdi (Escola Superior de Desenho Industrial da Universidade do Rio de Janeiro), que contou com a atuação profissional e pedagógica do brasileiro Alexandre Wollner, formado pela escola $\mathrm{UfG}^{[1]} \mathrm{em}$ UIm, Alemanha. Wollner foi o primeiro a colocar em prática uma concepção de design sob o pensamento metodológico racional, ou seja, a integração de arte com a tecnologia, além de influenciar direta ou indiretamente cerca de cinco gerações de designers brasileiros.

$\mathrm{Na}$ época, algumas escolas tiveram a oportunidade de desenvolver projetos acadêmicos do setor vestuário e têxtil. No entanto, desde a sua fundação até 0 ano de 1988, não foi criado nenhum curso que graduasse o profissional para desenvolver os produtos da confecção nacional de roupas. Ademais, os alunos que manifestassem interesse em desenvolver produtos de moda eram quase sempre desestimulados pelos professores dos cursos de desenho industrial ${ }^{[2]}$, e, posteriormente, design de produto e design gráfico.

No Brasil, até meados da década de 1980, antes de serem criados os cursos superiores de moda pelas Instituições de Ensino Superior, o brasileiro que desejasse estudar o assunto, ou o autodidata que desejasse aperfeiçoamento, era obrigado a freqüentar cursos no exterior. Ao mesmo tempo, grandes mudanças aconteciam na economia, as quais sinalizavam a necessidade de medidas urgentes diante da crise. 0 setor têxtil e de confecção decidiu então criar os primeiros cursos técnicos no Brasil e, dez anos mais tarde, colaborou para o aparecimento dos primeiros cursos superiores (Pires, 2002). Os cursos surgiram porque as condições materiais das cidades e sua produção têxtil estavam consolidadas e sua população comprometida com esse processo, a exemplo de São Paulo, Belo Horizonte, Blumenau, Jaraguá do Sul, Londrina, Maringá e Fortaleza.

Muito antes da criação dos cursos superiores, realizaram-se cursos para tratar do aprendizado dos processos de criação de moda, a exemplo de Marie Ruckie, francesa do Studio Berçot de Paris, que, desde 1978, visitava o Brasil todos os anos para dar aulas de estilismo. No Brasil e na França, Marie Ruckie formou uma importante geração de criadores, entre eles: Jum Nakao, Reinaldo Lourenço, André Lima e Ocimar 
Versolato, no entanto fundamentados nos valores estrangeiros.

Uma década mais tarde, Laïs Pearson visitou as mais conceituadas escolas da Inglaterra, França, Holanda, Áustria e Bélgica, e estudou o currículo da japonesa Bunka College para então elaborar o currículo de um dos primeiros cursos de estilismo no Brasil, que posteriormente se tornou referência aos demais cursos criados. Tanto o design quanto a moda nacional tiveram forte influência estrangeira.

0 Brasil tornou-se um dos quatro países com o maior número de cursos de design de excelência (Milanomadeindesign), mas tardou em estruturar cursos na Academia na área da Moda e posteriormente em Design de Moda. Antes disso, sem profissionais preparados, a função de designer de moda era assumida por leigos e autodidatas que aprendiam com o exercício da profissão. Aparentemente, 0 entendimento corrente era de que a atividade podia ser exercida por qualquer pessoa com certo talento artístico, informação de moda e "bom gosto".

No início da década de 1980, ressentindo-se de um profissional criador, com competência para conceber produtos de moda, as capitais dos estados de São Paulo, Rio de Janeiro e Minas Gerais, com a iniciativa do próprio setor e 0 apoio de algumas instituições de ensino, inauguraram os primeiros cursos profissionalizantes para o ensino da criação de moda no Brasil (Pires, 2002).

Depois, em 1988, na cidade de São Paulo, surgiu o primeiro curso superior de moda do Brasil. A idéia era formar um profissional com sólida instrumentalização teórico-prática, pronto a qualificar a produção brasileira de produtos de moda abrindo espaço para um campo profissional com novos conceitos de planejamento de produto (Pires, 2002).

Mais distante do histórico preconceito acadêmico da moda como uma especialidade do design, a cada articulação em defesa do design brasileiro, a moda brasileira vem sendo reconhecida, respeitada e incluída. No Relatório da Revisão da Tabela de Áreas do Conheci- mento Sob a Ótica do Design, resultado da consulta realizada em 2005 no Rio de Janeiro, sob solicitação da direção do $\mathrm{CNPq}$ à comunidade de pesquisadores na área de Design para obter sugestões de melhorias à Tabela de Áreas do Conhecimento, foram consultados cerca de duzentos pesquisadores de maneira direta, além de quarenta instituições, entre programas de pós-graduação, cursos de graduação e núcleos de pesquisa. $A$ moda foi apontada como uma das especialidades do design.

Ao acompanhar esta história há mais de duas décadas, posso afirmar que a aproximação entre moda e design - principalmente em seu aspecto formal - é inédita. A histórica resistência e tensão entre ambos, enfim, dá lugar a iniciativas conjugadas, potencializadoras de um olhar mais amplo em torno de sua função social.

Em 2006, na comemoração dos dez anos do PBD, Programa Brasileiro de Design, a Bienal Brasileira do Design, realizada nas instalações da Oca em São Paulo, buscou vencer conceitos equivocados da superficialidade do entendimento do design como "frivolidade estética". Assim, vislumbrou-se a correta compreensão de um processo que propõe soluções inovadoras que contribuem para o bem-estar das pessoas e a meIhoria das relações humanas. Lastimável foi que o vestuário não estivesse presente, além de alguns têxteis para interiores e adereços para o corpo. A moda poderia estar representada por nomes que têm se destacado na concepção de produtos de moda, como, por exemplo, as estampas desenvolvidas na década de 1970 pela Casa Rodhia que eram criadas por Volpi, Djanira, Aldemir Martins, Manabu Mabe, Alexandre Wollner, Ziraldo e Iberê Camargo, com textos de Millôr Fernandes e Carlos Drummond (Leal, 2002) ou, ainda, trabalhos desenvolvidos por Alceu Penna, Zuzu Angel, Carlos Miele, Ronaldo Fraga, entre outros.

Gradativamente, a moda se torna tema também das ações governamentais, uma vez que se reconheceu a grande importância do design na economia nacional. Em outubro de 2006, foi realizado em Brasília o II Encontro de Planejamento Estratégico do PBD, uma reunião para a discussão do planejamento estratégico para o período correspondente entre os anos 2007-2012.

0 evento foi uma promoção conjunta do Ministério do Desenvolvimento, Indústria e Comércio Exterior e da Agência Brasileira de Desenvol- 
traz do Conselho Nacional de Desenvolvimento Econômico Britânico a classificação das empresas conforme o uso do design em quatro estágios, a chamada "escada do design". Cada nível corresponde a um grau, ou melhor, degrau de competitividade. São eles:

vimento Industrial (Apex). 0 grupo foi composto por quarenta representantes de três segmentos: o setor produtivo, a área de design e a área acadêmica. A reunião teve por base de discussão as versões preliminares de documentos que identificavam as demandas por design do setor produtivo brasileiro, além de um panorama nacional e internacional das ações de design. Um destes documentos, intitulado Demanda de estratégias do design do setor produtivo brasileiro ${ }^{[3]}$, destaca sete segmentos: moda, móveis, utilidades domésticas, construção civil, bens de capital, equipamento médico-hospitalares e embalagens.

0 primeiro segmento apresentado pelo documento é Moda, definido como amplo e complexo por envolver diversas cadeias produtivas: a do vestuário, a têxtil e a de diversos outros produtos, tais como: jóias, bolsas, calçados, chapéus e acessórios. 0 texto define a abrangência como característica específica do setor e não encontra paralelo em outro segmento.

Mais adiante, o documento identifica quatro estratégias competitivas para a moda: volume, especialização, produtividade e fragmentação ${ }^{[4]}$ ou moda, sendo esta última a que mais carece de investimentos na concepção de novos produtos e a que mais utiliza o design. É o setor que mais investe em promoção de marca; contudo, no que diz respeito ao design, é o que mais copia "modelos produzidos nos centros difusores [Milão, Paris, Londres, Nova York. Austrália, Califórnia e Havaí], com adaptações ao clima e oferta de matéria-prima" (Centro de Design Paraná, 2006, p. 10).

0 item intitulado Demandas transversais afirma que a competitividade está menos na empresa e mais nas cadeias produtivas e arranjos produtivos e trata de alguns novos conceitos; isto é, um design que pensa não apenas nos negócios, mas, também, nos temas públicos como saúde, habitação, educação e o lazer. Em tal perspectiva, o meio ambiente também merece atenção nos critérios do design, o qual pode ter diferentes amplitudes em suas ações. Para ilustrar esta dimensão, o documento
1. Nenhum uso do Design. Nas empresas que se encontram neste degrau, outras disciplinas acumulam a função de introduzir funcionalidade ou estética ao desenvolvimento dos produtos ou serviços. 2. Design como Estilo. Nessas empresas o design é introduzido em um estágio já avançado do projeto, como num acabamento ou detalhe gráfico. 3 . Design como Processo. Neste degrau o design é visto como um método de trabalho. É integrado nos estágios iniciais do processo, combinando-se com a engenharia de produção, 0 marketing e outros setores da empresa. 4. Design como Estratégia. No degrau mais alto da escada, o design está incorporado na formulação da estratégia comercial da empresa. $E_{\text {, }}$ portanto, participa ativamente no fomento à inovação e no desenvolvimento de serviços e produtos. A partir dessa classificação podemos apontar algumas demandas do setor produtivo como um todo e que poderiam ser consideradas transversais. (Centro de Design Paraná, 2006, p. 5)

Para a transição do importado e reproduzido ao autêntico, é imprescindivel o crescimento da cultura de design nas empresas têxteis e de confecção para que galguem os outros níveis da escada do design. Para isto, a Academia tem papel-chave na criação de projetos pedagógicos, de acordo com a realidade do mundo do trabalho, de modo a formar profissionais capazes de sensibilizá-las para implementar o design como processo e estratégia.

Embora a pesquisa seja vital prática do design - o que implica material disponível que dissemine resultados de pesquisas científicas ou não -, o número de publicações em design de moda no Brasil é ainda muito incipiente. Em 2004, tive a oportunidade de publicar, na revista Fashion Theory um Banco de referências de moda na língua portuguesa. ${ }^{[5]} \mathrm{A}$ elaboração desta bibliografia de moda e áreas afins teve início nos primeiros anos da década de 1980, quando retornava de um curso de design de moda na Itália, 
numa época em que eram raríssimas as publicações na língua portuguesa que tratassem de assuntos pertinentes à moda. Esse banco é uma retrospectiva das obras publicadas nos últimos noventa anos, em língua portuguesa, entre as quais há edições publicadas em Portugal e traduções de obras de autores estrangeiros. No entanto, grande parte das (aproximadamente) 600 publicações elencadas é composta de autores nacionais. No material compilado em ordem alfabética, foram consideradas publicações em formato de livros, artigos periódicos, anais, catálogos, vídeos, teses e dissertações. Também foram consideradas algumas obras que tratam do tema apesar de não estar indicado no título.

$\mathrm{Na}$ última década, houve representativo crescimento na produção científica e acadêmica. Ao tornar disponíveis tais informações, inicialmente com a compilação de 400 títulos, pesquisadores e estudiosos da moda colaboramos para o avanço da pesquisa de design de moda no Brasil, como fonte de informação para formar o acervo das bibliotecas de moda do país e com a estruturação da rede, fundamental para a formação do sistema. ${ }^{[6]}$

Embora haja um número significativo de publicações cujo foco é a moda, raras delas tratam do design como aspecto constitutivo do assunto.

À medida que aumentam as publicações de livros, aumentam igualmente as teses e dissertações. Ao analisar o conjunto de 534 publicações, observamos que $60^{[7]}$ títulos dizem respeito a dissertações de mestrado e 13 teses de doutorado, todas na USP (Universidade de São Paulo) e, ainda, uma tese de livre-docência também na USP. Talvez esta tradição da USP em acolher pesquisadores com interesse na pesquisa em moda se deva a Gilda de Mello e Souza que, em 1950, defendeu no departamento de sociologia sua tese de doutorado, intitulada A moda no século XIX ${ }^{[8]}$.

Outro significativo indicador do crescente aumento da pesquisa em design de moda é a gradual representatividade de trabalhos inscritos nas quatro últimas edições do Congresso Brasileiro de Design realizado em Novo Hamburgo (2000), em Brasília (2002), São Paulo (2004) e Curitiba (2006). 0 P\&D é o maior Congresso da América Latina na área do Design. Realizado bienalmente desde 1994, o evento é voltado à discussão da pesquisa e do ensino de design no Brasil. A cada edição, observam-se 0 crescimento do volume de produção e a ampliação do conhecimento resultante de pesquisa aplicada e pesquisa básica na área do design de moda.

Em 2006, o design de moda representou 4\% e o design têxtil 1\% do total dos trabalhos recebidos pelo Congresso $^{[9]}$. $014^{\circ}$ Congresso Brasileiro de Ergonomia, organizado pela Abergo (Associação Brasileira de Ergonomia), em novembro de 2006, em Curitiba, teve pela primeira vez duas sessões técnicas intituladas Ergonomia na Moda, com trabalhos aplicados ao vestuário.

No Brasil, os estudos acadêmicos do design e da moda tiveram origens distintas. A cultura do design foi importada da Alemanha por brasileiros que estudaram na Escola Superior de Design de Ulm; portanto, com o rigor da ciência e do método que, segundo Guilherme Cunha Lima ${ }^{[10]}$, "ainda persiste na quase totalidade das escolas de design espaIhadas por todo o território nacional" (Designe, 2006, p. 11). Por outro lado, os cursos destinados à criação de produtos de moda, inicialmente desprezados pelo design, encontraram espaço quase sempre nas artes e passaram então, de 1988 em diante, a crescer em número, até somar um total de 112 cursos $^{[11]}$ superiores e 24 cursos de pós-graduação e $\mathrm{MBA}^{[12]}$. Como até 2004 os cursos de design não tinham diretrizes homologadas, aqueles com foco na concepção de produtos denominavam-se, em geral, Estilismo em Moda, Moda e Estilo ou apenas Moda. Desde então, por determinação do Ministério da Educação, como se todo curso com foco em moda tratasse de criação de produtos - design e estilismo - as instituições foram orientadas a adequar os projetos dos cursos às Diretrizes Curriculares do Design. Com isto, algumas questões vieram à superfície, como a inexistência de docentes designers de moda experientes em número suficiente para elaborar os projetos dos cursos e implementá-los. Entre 1988 e meados de 2000, formamos uma geração de estilistas que hoje coordena e ensina nos cursos de design de moda no Brasil, o que pode perpetuar uma compreensão do design como um processo parcial e 
estetizante.

Vale mencionar um exemplo da visão estilística na formação dos profissionais e, por consegüinte, disseminação de valores: a predominância do feminino na moda, que, por determinantes históricos, influenciou currículos e docentes a estruturarem seus programas numa preconceituosa estética feminina que privilegia uma minoria e marginaliza a maioria do biotipo da população brasileira, assim como o sexo masculino e todas as faixas etárias que não façam parte da juventude.

Hoje, representantes dos cursos de moda acompanham e participam dos grupos que debatem temas de interesse comum, a exemplo do Enesdi (Encontro Nacional de Ensino Superior de Design). Durante a $15^{\text {a }}$ edição, realizada em novembro de 2006 na UniRitter, em Porto Alegre, formaram-se quatro grupos de estudos. 0 primeiro deles foi responsável pelos temas de interesse da graduação e se dividiu em cinco subgrupos para tratar dos seguintes assuntos destacados como prioritários: 1) redução da carga-horária - o grupo manifestou-se contrário à redução da carga-horária mínima recomendada dos bacharelados para 2.400 horas; 2) a distinção entre os cursos de bacharelado e superior de tecnologia:durante 2007, uma comissão da Aend-Brasil (Associação de Ensino e Pesquisa de Nivel Superior de Design do Brasil) deve apresentar a definição do que é densidade tecnológica junto aos setores produtivos nos quais os tecnólogosatuam com o objetivo de facilitar a compreensão entre as duas modalidades de curso de graduação; 3) a interpretação das diretrizes curriculares do design: o grupo concluiu que a disciplina de projeto deve ser estrutural nos cursos para garantir a qualidade de ensino; recomenda também que a Aend-Brasil passe a nortear as Instituições de Ensino Superior quanto aos aspectos fundamentais a serem considerados durante a construção dos projetos pedagógicos; 4) cursos de capacitação docente: a proposta feita pelo professor Itiro, lida e bem aceita por todos os presentes, sugere a criação de um programa de capacitação docente realizado em Instituições que abrigam áreas de excelência no ensino de Design; 5) Sinaes (Sistema Nacional de Avaliação da Educação Superior), a tabela de classificação de área e o Enade: recomendou-se a reorganização da tabela da Unesco e OCDE ${ }^{[13]} \mathrm{com}$ a proposta de classificação semelhante do Design em órgãos do MEC, Ministério da Educação, e, posteriormente, a mesma classificação para a tabela do CNPq (Conselho Nacional de Desenvolvimento Científico e Tecnológico).

0 grupo recomendou também à grande plenária que se buscassem instrumentos que garantissem a presença de avaliadores com competência na área do design para compor as comissões de avaliação do Inep (Instituto Nacional de Estudos e Pesquisas Educacionais) e motivassem a inscrição de novos avaliadores. Até 2006, o banco de avaliadores contava com apenas 89 avaliadores (40 avaliadores institucionais e de curso e 49 apenas de curso).

0 tema Moda está presente no meu cotidiano desde 1982, quando obtive uma bolsa de estudos para um curso na Itália. De fato, muita coisa mudou desde então. 0 design, que era marcado por seu aspecto racional, rígido, preconceituoso, passou a conviver com a moda numa posição mais solidária e complementar.

Ao longo desse processo de transformação, a partir da década de 1990, reconheço-me partícipe e produtora desta nova leitura, em que a moda passou a constituir objeto de interesse social, acadêmico e científico. Por sua vez, também me reconheço engajada e pró-ativa no sentido de buscar despertar, em cada um dos setores e, sobretudo, naqueles ligados à indústria, a visão de que o design transcende a técnica ou a estética e pode ser entendido como cultura de projeto.

Contudo, para o avanço e a consolidação do design de moda brasileiro faz-se necessário o mapeamento das prováveis fontes de consulta, de cooperação, de publicação, de conservação, de formação e capacitação. Recentemente, em parceria com o Departamento de Design da Universidade Estadual de Londrina e o Centro de Design Paraná, assumimos a responsabilidade pelo conteúdo do design de moda no portal www.designbrasil.org.br.

0 DesignBrasil é uma iniciativa do Ministério do Desenvolvimento, Indústria e Comércio Exterior, mediante o PBD, coordenado pelo Centro de Design Paraná. 0 objetivo é promover a integração, a con- 
vergência e a cooperação entre as diversas ações na área do design em todo o país. 0 DesignBrasil incentiva a interação e a troca de informações entre profissionais, estudantes, empresários e todos os que vivem design no Brasil.

Uma das maneiras de consolidar o design de moda é organizar uma rede de informações que estruture o tecido que gerará conhecimento e formará a cultura de design de moda brasileiro. Por ora, o setor ainda está fragmentado e em fase de fortalecimento. A iniciativa do portal DesignBrasil, criado com este objetivo, é coletivizar informações, a exemplo daquelas levantadas no final de 2006, quando constamos que o país contava com 112 cursos superiores (55 bacharelados; 42 tecnológicos; 15 seqüenciais) e 26 de pós-graduação (um mestrado; 20 especializações; cinco MBA); seis associações; 14 institutos, centros e núcleos de estudos; quatro bibliotecas especializadas, duas tecitecas e uma modateca; sete museus; quatro editoras com perfil de publicações com o tema moda; 31 eventos; duas expedições internacionais; e ainda prêmios e concursos, regionais em sua maioria.

Como evento específico para os estudos da moda, contamos com o Colóquio Nacional de Moda, criado em 2005, por Kathia Castilho, da Universidade Anhembi Morumbi, e Maria de Fátima de Mattos, da Universidade Moura Lacerda. Com esta iniciativa, foi dado mais um passo para o reconhecimento da moda como campo do saber, quando se realizou a primeira edição, em Ribeirão Preto, a fim de agregar professores, estudiosos e pesquisadores de moda, para promover o estudo e a divulgação de assuntos relacionados ao ensino, à pesquisa e à produção acadêmica na área.

A edição 2006 aconteceu na Universidade Salvador - UNIFACS. Em 2007, a anfitriã do evento é a Faculdade CIMO (Centro Integrado de Moda) de Belo Horizonte e, no próximo ano, o Colóquio acontecerá na Feevale em Novo Hamburgo.

Atualmente, a tensão que há entre o design e a moda é muito inferior se comparada à década passada e tem sido superada de modo gradativo. 0 tema que deve pon- tuar as discussões emergentes é, sobretudo, de ordem conceitual, especialmente no que diz respeito ao Ensino Superior.

Por ocasião do I Fórum de Escolas de Moda, transcorrido durante o II Colóquio Nacional de Moda, em outubro de 2006, na Universidade de Salvador, na Bahia, compareceram 24 representantes de Instituições de Ensino Superior. Os temas que suscitaram discussão giraram em torno das diretrizes curriculares específicas de design, que não contemplam em seu conteúdo outras áreas como gestão, figurino, jornalismo, entre outras, e, no entanto, são exigidas pelo MEC.

Também foram discutidos temas sobre a constituição da moda como um campo de saber; a redução da carga-horária mínima dos cursos; o campo de estágio e a empregabilidade; o nivel formativo dos ingressantes nos cursos, e a construção dos projetos pedagógicos dos cursos. Este último tópico, sem dúvida, tem preocupado Instituições de Ensino Superior e especialistas avaliadores do MEC/Inep. Debateram-se também questões pontuais como os critérios do processo Exame Nacional de Desempenho de Estudantes.

Durante os anos de atuação na presidência da área de design da Setec (Secretaria de Educação Tecnológica) do MEC e, por consegüinte, também como especialista avaliadora dos cursos de design, constatei dificuldades comuns em quase todos os projetos político-pedagógicos, dentre as quais destaco: projetos concebidos sem consistente justificativa e definição de um perfil profissional de formação, elaborados antes da concepção do curso; inexistência de investimentos na construção dos projetos dos cursos; baixa coerência entre a justificativa, o perfil e as unidades curriculares; $e_{1}$ ainda, pouco conhecimento das metodologias de ensino. Provavelmente, a origem desses problemas deve-se à recente criação dos cursos superiores de design no Brasil (1963), moda (1988) e design de moda (1998) e também do fenômeno da expansão dos cursos de design em todo o território nacional nas últimas décadas.

Muitas alternativas surgem enquanto ainda restam reais desafios a serem superados, para que se consolide uma nova cultura de projeto dos bens de consumo para o corpo. Devemos trabalhar conjuntamente e defender que as universidades invistam mais em pesquisa e extensão para que uma nova cultura de projeto marque a formação dos novos designers de moda. Do mesmo modo, é preciso que as indústrias estejam dispostas a acolher e reconhecer o valor da adoção de melhores 
procedimentos relacionados ao design.

Diante das grandes questões do nosso tempo, das problematizações que, dia-a-dia, se fazem mais reconhecidas, sobretudo quanto às questões de produção, consumo e sustentabilidade, torna-se recomendável que a pesquisa prossiga sob uma abordagem de desenvolvimento para os produtos, serviços e sistemas.

Além dos caminhos já conhecidos, outros laços entre a moda e o design devem ser considerados para que se amplie o acesso a outra estética relacionada à moda: pensá-la sob uma ótica de justiça social, de economia, e sob uma perspectiva de sustentabilidade ambiental. Estejam de um lado ou de outro do balcão das lojas - vendedores e compradores - já é tempo que mais pessoas tenham consciência do que realmente necessitam consumir. A educação, a informação e a análise que contribuam para um novo paradigma de qualidade de vida

\section{REFERÊNCIAS}

Centro de Design Paraná. Demanda de estratégias do design do setor produtivo brasileiro. Curitiba: Centro de Design Paraná, 2006. Disponivel em: <http://www. designbrasil.org.br/portal/acoes/PBD_Plano_ Estrategico_v04_04_07_c.pdfs

DESIGNE. Rio de Janeiro: IAV, Instituto de Artes Visuais da UniverCidade, $n^{\circ}$ 6, 2006.

LEAL, Joyce J. Um olhar sobre o design brasileiro. São Paulo: Objeto Brasil; Instituto Uniemp; Imprensa Oficial do Estado, 2002.

Milanomadeindesign: territorio uomini idee. Roma: Contrasto, 2006.

PIRES, Dorotéia B. A história dos cursos de design de moda no Brasil. Revista Nexos: Estudos em Comunicação e Educação. Especial Moda. São Paulo: Universidade Anhembi Morumbi, ano 6, n 9, 2002.

STRADA, Nanni. Moda design. Milão: Editoriale Modo, 1998.

VACCARI, Alessandra. Lo studio dell'abbigliamento tra arti decorative e design. In: Sosrcinelli, Paolo. (org.) Studiare Ia moda. Milão: Mondadori, 2003.

\section{NOTAS}

${ }^{[1]}$ No periodo de sua existência, de 1953 a 1968, influenciada pela Bauhaus, a UfG foi uma das mais importantes escolas contemporâneas de design, destacando-se como instituição internacional no campo do ensino, do desenvolvimento e da pesquisa na área do design industrial.

${ }^{[2]}$ No I Fórum de Dirigentes de Cursos de Desenho Industrial realizado em abril de 1997, em parceria com a Universidade Federal de Pernambuco e da Ceearte/Sesu/MEC, foi encaminhada ao MEC a proposta de adotar a denominação Design em substituição ao nome de Desenho Industrial para os cursos de graduação na área. A partir de 1998, com a criação da Comissão de Especialistas de Ensino de Design (Cee-Design), a denominação Design foi oficializada e passou a ser usada pelas IES, quando da abertura de novos cursos. As Diretrizes Curriculares Nacionais, alinhadas com a orientação do Sesu/MEC, mantiveram a denominação Design para a área.

${ }^{[3]}$ Todos os documentos, Demanda por Design, Panorama Nacional e Panorama Internacional, podem ser encontrados na integra no site www.designbrasil.org.b

${ }^{[4]}$ Para Porter (1991), "um importante meio estrutural, no qual numerosas organizações competem, é a indústria fragmentada, em que nenhuma companhia possui uma parcela de mercado significativa nem pode influenciar fortemente o resultado da indústria. Comumente, as indústrias fragmentadas se constituem de grande número de empresas de pequeno e médio portes. A noção essencial que faz dessas indústrias um meio competitivo bastante peculiar é a ausência de líderes de mercado com influência sobre a atuação da indústria" (Goularti; Jenoveva, 1997, p. 55)

${ }^{5}$ Fashion Theory: a Revista da Moda, Corpo e Cultura. São Paulo: Anhembi Morumbi, Edição Brasileira, v. 3, no 1, mar. 2004.

${ }^{[6]}$ Hoje, o banco de dados é constantemente atualizado e encontra-se disponivel no portal www.designbrasil.org.br [7] Nas seguintes Instituições de Ensino Superior: 19 USP, 10 UFSC, 7 PUC-SP, 6 PUC-RJ, 5 UFRJ entre outras Instituições.

${ }^{[8]}$ Pesquisadora na área de estética e filosofia, falecida em 2005. Em 1950, publicou o artigo "A moda no século XIX" na Revista do Museu Paulista. Em 1987, publicou O espírito das roupas: a moda no século XIX, pela Companhia das Letras.

${ }^{[9]}$ Disponivel em: <http://www.design.ufpr.br/ped2006/home.htm> Acesso em: 12/10/2006.

${ }^{[10] P h D, ~ c o o r d e n a d o r ~ d o ~ M e s t r a d o ~ e m ~ D e s i g n ~ d a ~ E S D I / U E R J . ~}$

[11]Os estados com maior número de cursos de graduação são: SP (30); SC (17); RJ (11); PR (10); MG (10); RS (6).

${ }^{[12]}$ Os estados com maior número de cursos de pós-graduação e MBA são: SP (11), sendo um destes em nível de mestrado; PR (5).

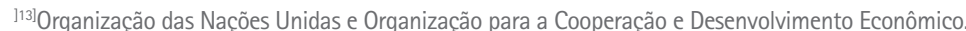

